\title{
Innovative Second Language Speaking Practice with Interactive Videos in a Rich Internet Application Environment
}

\author{
Juan A. Pereira ${ }^{1}$, Silvia Sanz-Santamaría ${ }^{1}$, Raúl Montero ${ }^{2} \&$ Julián Gutiérrez $^{1}$ \\ ${ }^{1}$ Department of Computer Languages and Systems, Faculty of Computer Sciences, University of the Basque \\ Country, Donostia-San Sebastián, Spain \\ ${ }^{2}$ Department of English and German Philology and Translation \& Interpretation, Faculty of Arts, University of the \\ Basque Country, Vitoria-Gasteiz, Spain \\ Correspondence: Silvia Sanz-Santamaría, Facultad de Informática, Po Manuel de Lardizábal, 1, 20018 \\ Donostia-San Sebastián, Spain. Tel: 34-943-018-088. E-mail: silvia.sanz@ehu.es
}

Received: September 13, 2012

doi:10.5539/ies.v5n6p272
Accepted: September 24, 2012 Online Published: November 19, 2012

URL: http://dx.doi.org/10.5539/ies.v5n6p272

\begin{abstract}
Attaining a satisfactory level of oral communication in a second language is a laborious process. In this action research paper we describe a new method applied through the use of interactive videos and the Babelium Project Rich Internet Application (RIA), which allows students to practice speaking skills through a variety of exercises. We present an experience with a number of interactive video exercises used in a real world scenario with nearly 100 students of English as a Second Language at a Spanish university. The use of interactive videos with the Babelium application has allowed our students to record their voices and faces (using microphones and webcams) and to be weekly evaluated according to a set of defined oral evaluation criteria. Based on the results of a survey conducted at the end of the semester, we demonstrate that the students involved in this research experiment have significantly increased the number of hours devoted to speaking practice comparing to the methods used in previous years. Finally, this paper suggests new types of interactive video-based exercises to further improve the outcome of the speaking practice with the help of the Babelium Project application.
\end{abstract}

Keywords: speaking practice, rich internet applications, English as a second language, interactive videos, reading practice, action research

\section{Introduction}

\subsection{Teaching and Learning L2 Phonetic and Oral Skills in Spain}

The IPA or International Phonetic Alphabet is the most widely used method of teaching the pronunciation of the English language. According to the Merriam-Webster dictionary, pho-net ics, /fə-ne-tiks/, is the system of speech sounds of a language. The complexity of speaking correctly has been well recognized through a close look at the key components of oral production identified by researchers over the years. Teachers taking the time to stress the importance of phonetics will help students to better communicate in the English language. Short-term laboratory perceptual training procedures expose that exercises in phonetics are beneficial in the learning of English as a second language (Bradlow, Akahane-Yamada, Pisoni, \& Tohkura, 1999). Spanish students have an enormous problem when they have to speak English. The main reason derives from the fact that out of the 36 English phonemes, Spanish students can only recognize 18 from Spanish (Goldstein \& Iglesias, 1996). English has a lot of monosyllabic words while Spanish is polysyllabic. Moreover, intonation, stress, and rhythm are essential in communication and the two languages are very different from each other in these respects. Alía, González, Membrillera, Molinero, \& Serrano (2005) presented an article where they expounded that English intonation is completely opposite to the Spanish one. Gómez (2009) analyzes, among others, studies (Cenoz \& García Lecumberri, 1997; Cenoz \& García Lecumberri, 1999) related to Spanish students of English as a second language and she concludes that "Spanish learners of English showing that discrimination instruction on English vowels and diphthongs also produced significant gains". Cenoz \& García Lecumberri (1997) found, however, that these gains were not the same for all subjects, training proving more efficient in the case of students with poorer performance in pre-test. Intonation is also very difficult to teach because we need to focus not just on general meanings such as questions or negations, but on others related to the speaker's attitude. For this reason, some messages are not clear for the Spanish speaker when they have to face a new rhythm pattern such as the English one. English rhythm 
produces confusion in Spanish speakers who try to participate in the conversation. When students have to read aloud a text, new problems appear because, as Jiang \& Grabe (2011) affirm, "fluent word recognition involves an interaction of activated orthographic, phonological, and semantic and syntactic processes. Research on reading has shown that beginning readers need to establish strong linkages between orthographic forms and the sounds of language".

There are also several socio-cultural factors against English acquisition. Spain is a country where the bulk of foreign audiovisual material has always been translated into the mother tongue. Before Digital Terrestrial Television (DTT) system reached every Spanish household in 2010, our cinemas or TV channels had neither films nor series which we could watch in their original versions. We were not used to listening to or speaking English and, when we had to do it, we felt uncomfortable. It implied that our society thought it did not need English, but the situation is changing and Spanish people have started to realize its importance.

\subsection{Babelium Project}

Babelium Project (http://babeliumproject.com), henceforth BP, is a new Rich Internet Application (RIA) for practicing oral production in a collaborative way, developed by the Spanish Hypermedia and Multimedia Research Group (Grupo Hipermedia y Multimedia, GHyM) of the University of the Basque Country. The source code (http://code.google.com/p/babeliumproject) of this project has been published under a free software license (GPLv3).

Babelium emerged with the aim of integrating users in an international community to practice their L2 oral skills, since it is probably one of the most difficult skills to acquire and train. Speaking in a foreign language often unnerves students because they are uncertain about their knowledge, they feel uncomfortable and they are afraid of failure (Tanveer, 2007; Park \& Lee, 2005). Other problems related with practicing L2 oral skills include lack of time, money or the impossibility of moving to the region where the target language is spoken. BP's aim is to offer users a tool for producing and sharing interactive video exercises in different languages. Users can upload their own videos from their computer (Figure 1) or just record them ad-hoc using their web cams. It is also possible for them to reuse other videos from the Internet (observing licenses) and practice L2 oral skills using those videos in Babelium as we will explain in following sections. It is important to mention that the Babelium tool can be used directly from the browser without needing to install any other application.

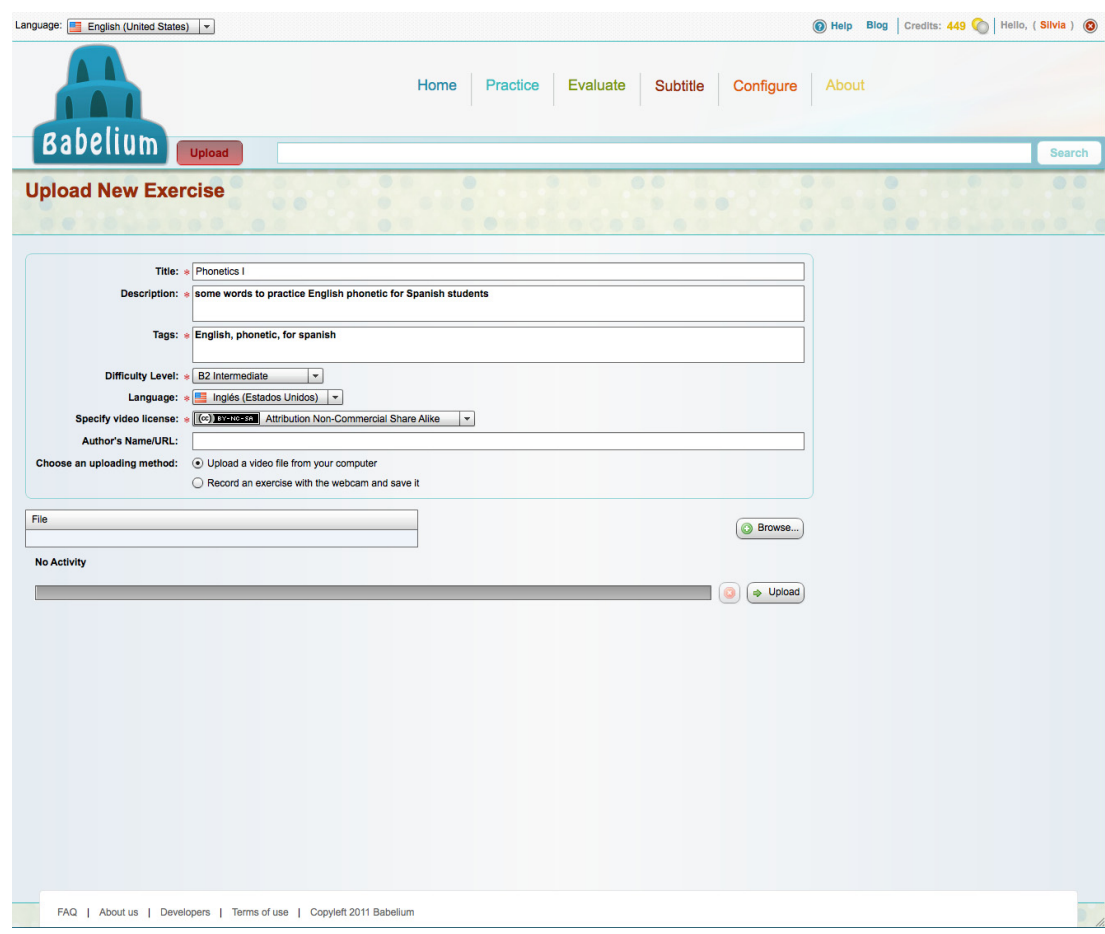

Figure 1. Upload new video from computer/the Internet

The first type of exercise that we proposed to practice the speaking skill using BP consisted in dubbing a famous 
character from a film or a series. The user could choose to take the role of one of the characters that appear in his/her favorite film and perform the associated role while speaking in real time as if he/she was the actor. After selecting the role the user wants to dub, the video starts playing. Then, the selected role appears on the screen (Figure 2, red arrow) and when the user's time to speak comes, the Babelium application records their voice via the microphone. Users also have the possibility to record themselves using a webcam, which is highly recommended as previous studies demonstrate that active use of new technologies is highly beneficial in the learning process (Frey, Houlton, \& Gruis, 2010). Just as in real life, users have a limited time-frame to record themselves while speaking in English, exactly the same amount of time as taken by the line of the chosen character in the original video. For this reason, users' feelings while doing the exercise are very similar to the ones they could experience in real conversations.

It is also possible for users to add new clips and subtitles (Figure 3), thereby creating exercises which may then be used by others, with the option of showing/hiding subtitles in real time during playback and recording. According to the dual coding hypothesis of Paivio (1986), and as Baralt, Pennestri, \& Selvandin (2011) have demonstrated, "presenting learners with visual and auditory input concurrently, may help them to process and to retain vocabulary more effectively".

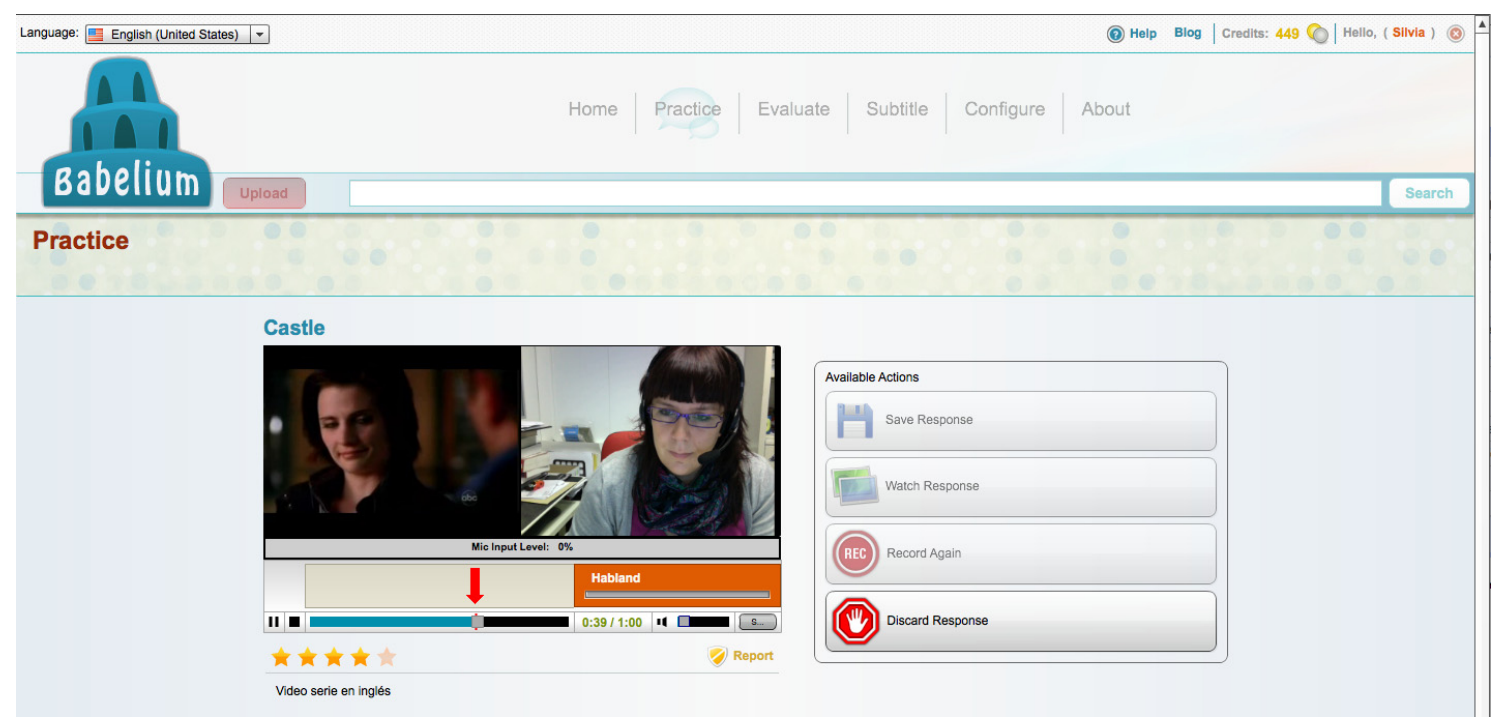

Figure 2. Record and exercise

After taking into account teachers' suggestions and using the interactive mechanism explained above, we added two new types of interactive video exercises: one for reading aloud isolated words and short sentences to practice specific sounds in English, and another one where students have to record themselves speaking aloud about a specific topic.

Users can display the video as many times as they need before recording. When recording an exercise, it is possible to stop it at any moment and start again from the very beginning. When they complete the dubbing of the conversation or any other task related to the other activities offered, they have the option of reviewing their work. We offer several options to do it: 1) display the video exercise (mixing the original clip with the one recorded by the student), 2) display only the recording, 3) discard the exercise, or 4) save and publish it (when the student deems the final result satisfactory). 


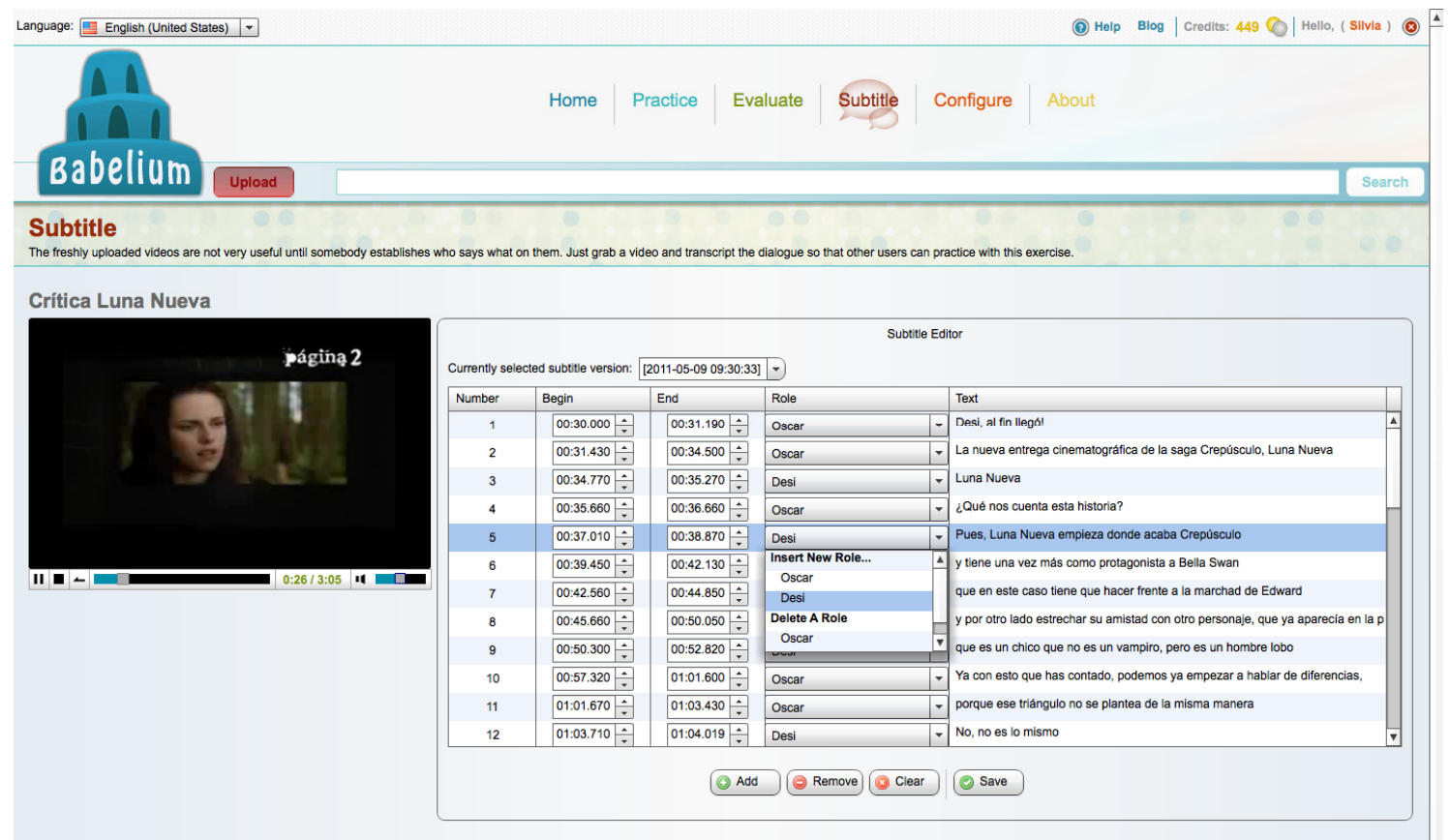

Figure 3. Add subtitles

When users publish their video exercise, the video moves to the assessment phase and becomes available for other users who will evaluate it. This evaluation can also be done collaboratively. As an example, we can present two different experiences. The first one was done with English teachers who used Babelium in the English class and corrected students' performances collaboratively in class; the second one, with regular users who had recorded themselves using our system and were then evaluated by other peers who were native in the recorded language and were using the tool both as users and evaluators.

On this stage, users have to evaluate the speaking exercise (Figure 4) according to 5 items: 1) Intonation and Accent, 2) Pronunciation, 3) Rhythm, 4) Spontaneity and 5) Overall Score. It is also possible to add feedback with a text comment and/or a video comment, which could be useful to help users when they want to correct and improve their pronunciation.

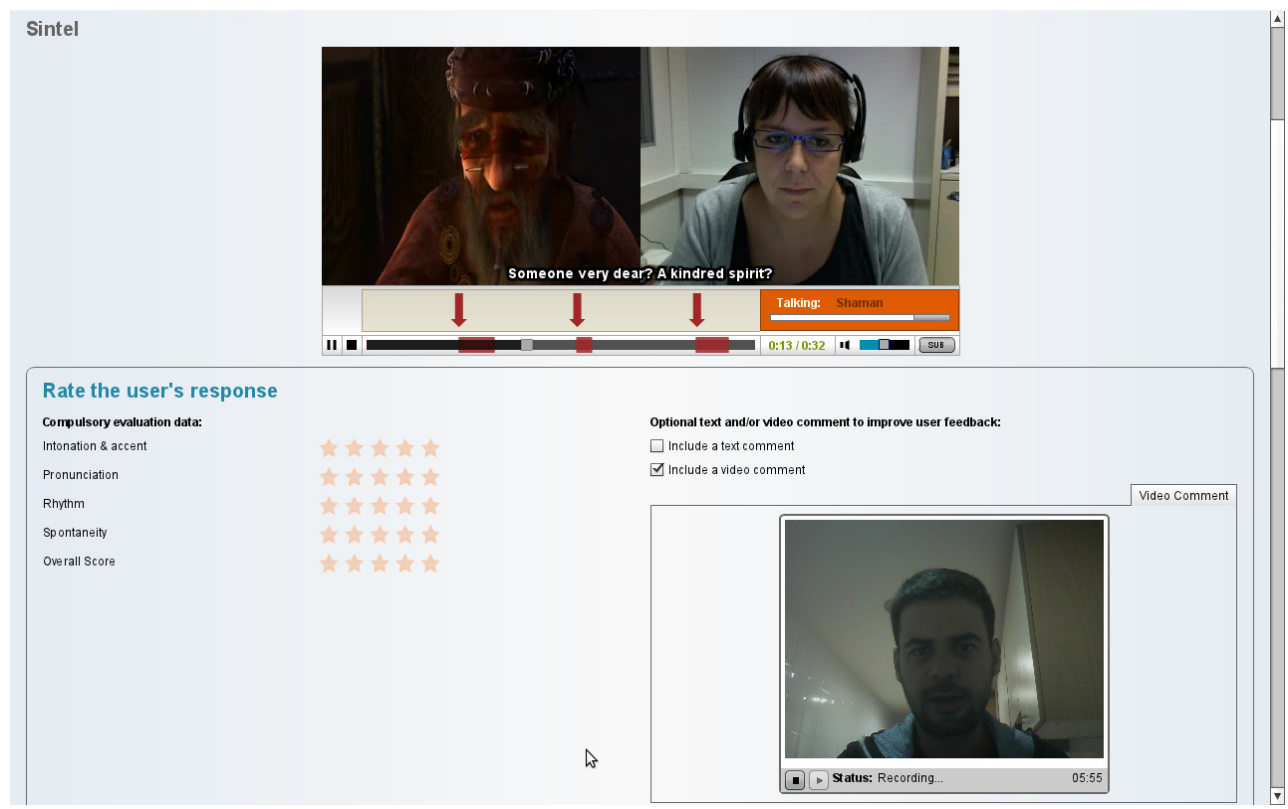

Figure 4. Assess an exercise 


\subsection{Real Speaking Practice}

During the EDUTEC 2010 conference about the use of Web 2.0 and related technologies in education, GHyM met and talked about the possibility of using Babelium in an English classroom to improve L2 pronunciation and phonetic skills.

The English teachers found Babelium a very interesting tool for meeting their subject's requirements, as well as attaining cross-curricular competences and also as an innovative application to engage students in improving their speaking skills through real practice.

On the basis of this meeting, the authors of this paper developed a methodology to implement Babelium in the English classroom and decided to compile students' opinions about it. The whole experience, detailed in this paper, will be used to test a new way of practicing English while using new technologies.

The following sections explain in detail our experimental research using Babelium Project to support real life practice in English as a Second Language with the aim of improving speaking skills. In the section titled The Experience, we detail the data about participants, purpose, material and the development of the study. The next section, Results, presents some statistical data extracted from the survey students filled out. In Discussion, we debate the obtained results and teachers' impressions of the experience and enumerate recommendations they propose for other L2 teachers. Finally, we highlight a number of conclusions drawn from the overall experience which will establish directions for future research related to Babelium Project.

\section{The Experience}

\subsection{Participants}

The experience was carried out with two groups of students who were doing the subjects English II and English III, both from the BA of Pre-Primary and Primary Education at the Public University of Navarre, Spain. English II was presented as a compulsory subject in the second course of the BA. For our study we used a subgroup of 30 students from the Repetition Group (98 students, divided into 3 groups). According to the Common European Framework of Reference for Languages (CEFR), the level of the selected group was B2 (B.2.1. initial stage). English III was also a compulsory subject at the second course of the BA, with 240 students divided into 4 groups. One group with 60 students participated in the study. The level of this group was B2 (B.2.2. advanced stage). The main objective of both subjects was to develop students' oral and written level of English to achieve an upper-intermediate level (B2) in English. Among other objectives, students attending these courses should acquire a good command of oral skills with special attention to the pronunciation of individual sounds and of words in connected speech.

\subsection{Purpose of the Study}

For an L2 student the only way to speak in the target language is to spend as much time as possible speaking that language, while using the intonation, expressiveness, pronunciation, stress, and rhythm accurately. The purpose of our study was to explore the integration of current technology and an innovative open-source web system called Babelium to improve and extend students' oral practice activities in English as L2.

Due to the nature of the system used, Babelium, there were also other more specific aims to make the teacher's work more pleasant and effective:

- To create an online repository of teacher-proposed video exercises and answers to these provided by associated students, which would serve students and teachers as a collection of the best and worst examples of task completion.

- To decrease evaluation time, due to it is one major problem for L2 teachers when practicing and evaluating oral skills.

\subsection{Material}

In this experience we designed 4 exercises:

1) Pronunciation practice. It consists of a video with a series of isolated words which are displayed for 3-4 seconds each; students must pronounce each one during this period of time. These words have been selected from New English File Upper-Intermediate (Oxenden \& Latham-Koening, 2008). The following isolated words were used: fish, tree, cat, car, clock, horse, bull, boot, computer, bird, egg, up, train, phone, bike, owl, boy, ear, chair, tourist, parrot, bag, key, girl, flower, vase, tie, dog, snake, zebra, shower, television, thumb, mother, chess, jazz, leg, right, witch, yacht, monkey, nose, singer.

2) Reading Aloud A. In this exercise a video clip appears showing an adaptation from the novel Small World (Lodge, 1995) (duration of the clip selected for adaptation: 1'30") which the teacher considers suitable for a B2 
level (B.2.1.). This clip is divided into shorter fragments displayed during 13-15 seconds each. Students must read the adaptation, observing the allocated time.

3) Reading Aloud B. The video clip shows a fragment (not adaptation) from the novel The Explorer of the Chest (Gilete, 2010) (duration of the selected clip: 5') which the teacher considers suitable for a B2 level (B.2.2.). The procedure is similar to the exercise above.

4) Storyboard. Students must create a short film (2'30") using a webcam, smartphone or any other video-recording device, on the basis of 6-8 frames they have previously selected from the storyboard of the novel The Explorer of the Chest.

In order to fulfill subjects' objectives, students from English II carried out exercises 'Pronunciation practice' and 'Reading Aloud A', while students from English III worked on exercises 'Reading Aloud B' and 'Storyboard'.

The materials at the disposal of the English II students were: 1) Babelium Project Student's Guide, 2) a brief guide about the use of the system, some tips and tricks and practical information for executing the exercises, 3) Introduction to Phonetics. A brief explanation about basic concepts related to Phonetics and Phonetic symbols (long vowels, short vowels, diphthongs, consonants and other symbols such as stress and syllable division), 4) Exercises on BabeliumProject.com ready to execute upon logging into the platform.

The materials available to English III students were: 1) Babelium Project Student's Guide, 2) exercises on BabeliumProject.com, 3) the storyboard for The Explorer of the Chest provided to them by their teacher to develop exercise 4.

All the students needed a computer connected to the Internet, a webcam and a microphone. Almost all of them had this equipment at home. The opportunity to use the University computers with the proper equipment was provided to the few students who did not have computers at home.

\subsection{Development}

In this section we explain in detail how the two main exercise types in this action research were developed.

\subsubsection{Pronunciation and Reading Exercises}

Before starting with the recording, the teacher explained to students what Babelium was, how to use it, and the exercises that students had to record ('Pronunciation' and 'Reading Aloud A' for English II students and 'Reading Aloud B' for English III students). The teacher also devoted three classes (one hour each) to explain the basic aspects of phonetics and focus on the words that students should record later. Finally, the teacher dedicated one class to a practical demonstration where he explained how to execute the exercises in the Babelium application, showing recording examples prepared on purpose. After these sessions, students had a period of two months to individually complete all the exercises. Once students published their exercises, all of them were automatically stored in the Babelium application. Finally, after the activity, students received immediate feedback on their exercises, including text and video commentaries. Once they finished, they had to complete a questionnaire where they explained how they feel about this new way of improving their oral skills in English.

\subsubsection{Storyboard Exercise}

Before starting with the exercise recording, the teacher revised the Babelium Students' Manual with the students of English III (they had already done the Reading Aloud B exercise). Later, students were asked to read The Explorer of the Chest in their own time. The novel was the base for the storyboard exercise.

After these sessions, the students received a storyboard for the aforementioned novel. Each student had to choose two pictures, or frames, from the storyboard and link them with his/her group. They were divided into groups of 3 or 4 people so each group had a collection of 6 or 8 frames, depending on the number of members. In order to develop the activity, each group had to create a short film (2'30" max.) on the basis of their frames. This short film could be developed as a common play, shadow play, puppet theatre or any other interpretation they wanted. This exercise had also to be uploaded to the Babelium application.

Finally, after the activity, the teacher devoted 2 classes ( 2 hours) to display the outcome of the groups' work and to comment on it, where students analyzed and evaluated not only their own production, but also the ones performed by their classmates during the semester.

\section{Results and Findings}

Once both English courses ended, students were asked to fill out 2 questionnaires, previously prepared by GHyM and made available for teachers at Google Docs Forms. Both questionnaires were entirely anonymous and directly accessible from the Babelium web page. Questionnaire A was about students' L2 oral practice habits, students' 
attitude to new technologies and social networks, and their experience using Babelium Project. Questionnaire B was about the entire subject (English II or English III): their opinion about its methodology, and what they liked best or would change. Our study is mainly centered on the questionnaire A, but there is also some relevant data from questionnaire $\mathrm{B}$.

Skills: speaking, reading, listening

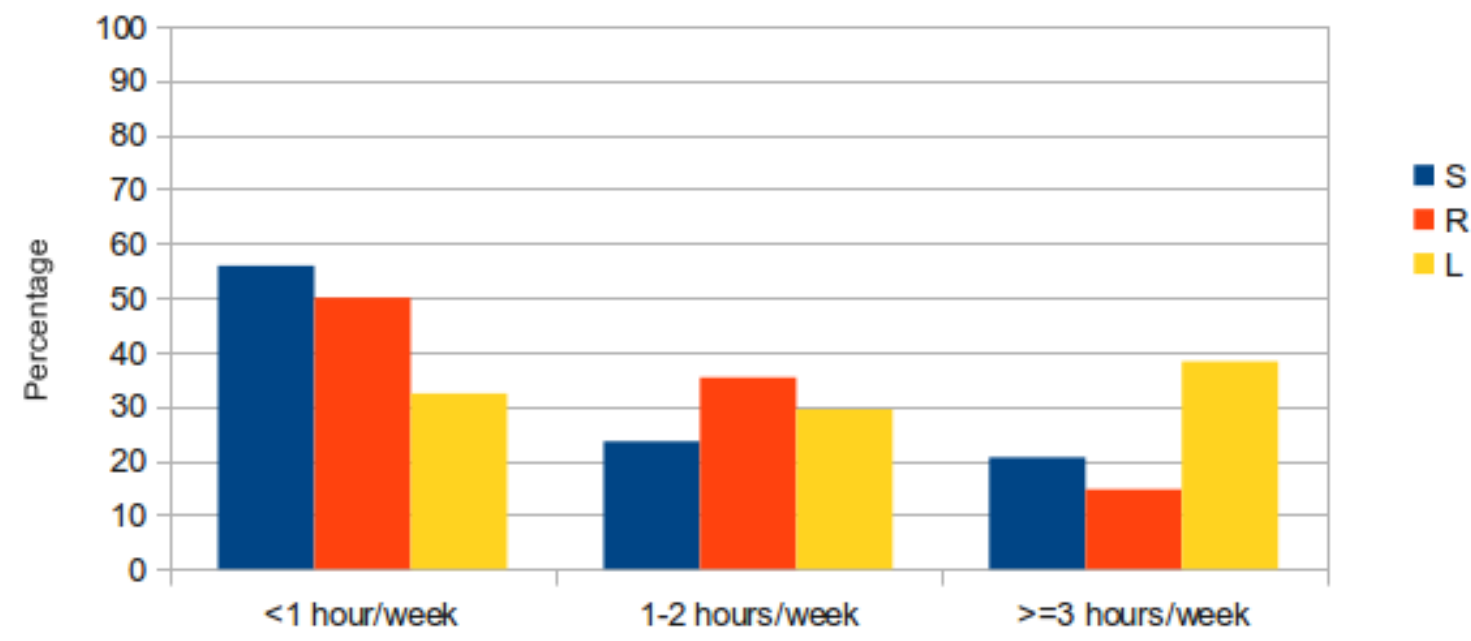

Figure 5. Weekly hours devoted to English learning

As far as the oral competence is concerned, it is worth noting that more than $55 \%$ of the students practice speaking less than 1 hour per week and more than $80 \%$ practice their oral skills less than 2 hours per week (Figure 5). This is an alarming fact which supports several negative conclusions about the English language mastery in Spain, as shown in the study of Education First (2011), which has placed Spain in the low 24th position in the worldwide ranking in reference to the knowledge of English.

This data contrasts markedly with what students indicate in Figure 6 regarding the question: "How many hours a week do you think you should spend practicing English to pass the speaking exam of your current level (B2)?”

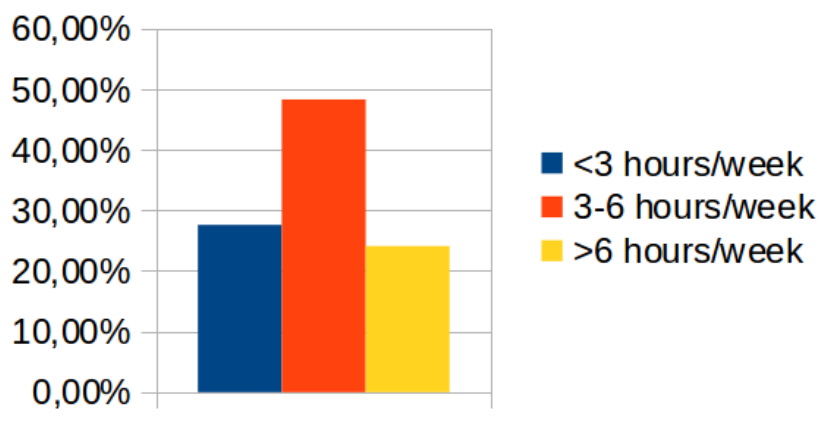

Figure 6. Students-estimated time practicing speaking necessary to pass the official B2 English exam

Most of the students $(72,4 \%)$ think that they should practice at least 3 hours/week to pass the exam. Babelium Project has allowed English learners to improve significantly the time they spent practicing oral expression. In our action research, the time each student has committed to speaking in English, whether by practicing to record his/her answer or by doing the final recording, has been, on average, nearly 163 minutes (more than 2,7 hours) in 4.5 days (with a maximum of 321 minutes in 2 days), as shown in Figure 7 . In other words, on average, they have practiced the speaking skills for 35.76 minutes a day (with a maximum of 160.5 minutes a day). 

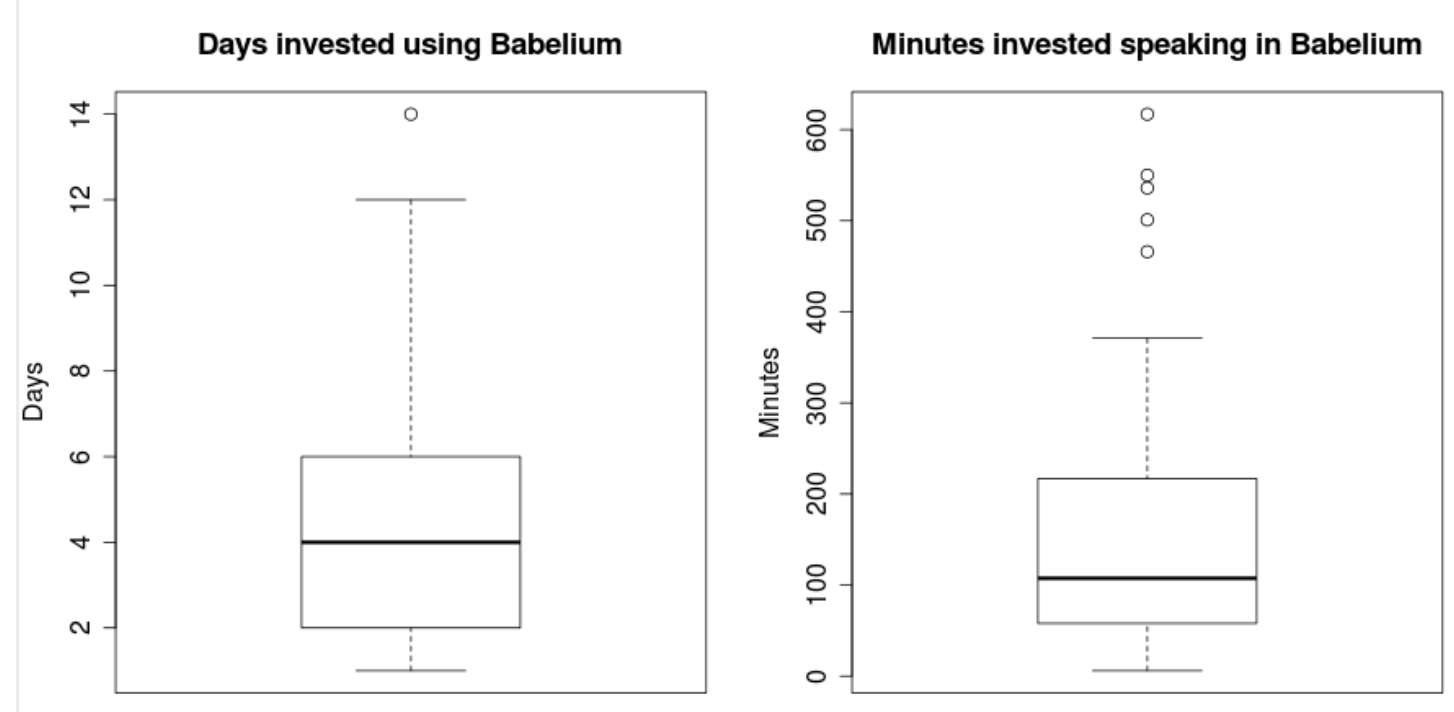

Figure 7. Summary of students' dedication to oral practice using Babelium

With regard to the exercises created specifically to improve oral skills (Figure 8) and the question: "Which is the exercise from Babelium Project that helps more to improve your oral skills?", $63 \%$ of students consider that 'Reading Aloud' is one of the best exercises to improve oral skills, while $50 \%$ of students also point out 'Storyboard' as a very good exercise to achieve that aim. On the other hand, 'Pronunciation' exercise seems to be the least valued, only $1 \%$ of students believe that this is a good exercise to improve L2 speaking practice.

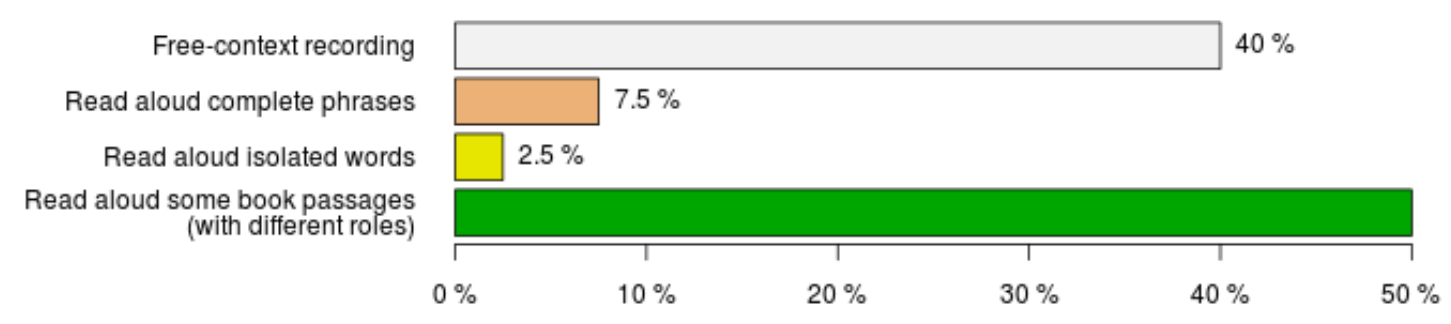

Figure 8. Best exercise to improve oral skills

According to the length and speed of video exercises, Figure 9 shows that the great majority of students are satisfied with them: $94 \%$ of students consider the length of the videos to be appropriate.
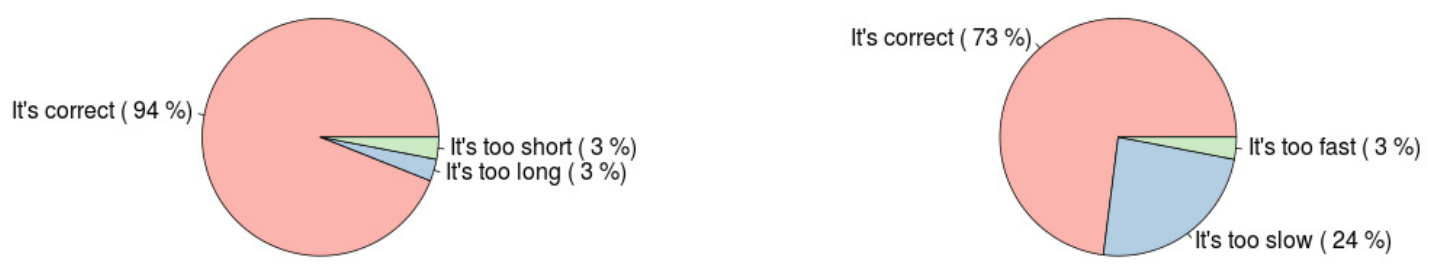

Figure 9. Opinion about the length of video exercises (left) and their speed (right)

When students were asked to suggest other types of exercises that could be implemented in Babelium Project, $16,6 \%$ of them said there was no need for more formats, whereas others point out interesting ideas, some of which 
are already in the strategic lines of Babelium Project (please note that these are exact words from the students, so the reader could find some mistakes): "Interactive speaking in real time", "Choose texts according oneself likes", "Watch some images while listening. Something short", "Speak alone, each week, during 5' about a specific topic", "Make short films related to the degree course", "Make interviews between the members of each group", "Speak online between classmates", "Self-expression through speech", "More exercises for reading", "Different exercises in each group so we can complement each other".

Regarding the use of multimedia devices and social network utilization, it is striking that although a great majority of students regularly use social networks (Figure 10) to share personal details and pictures, there are still many students $(72,5 \%)$ reluctant to use the webcam for recording the video exercises who said they would not use it if they were not be forced by the teacher. Moreover, only 55\% of students have recorded themselves, at least once, to hear their own voice.

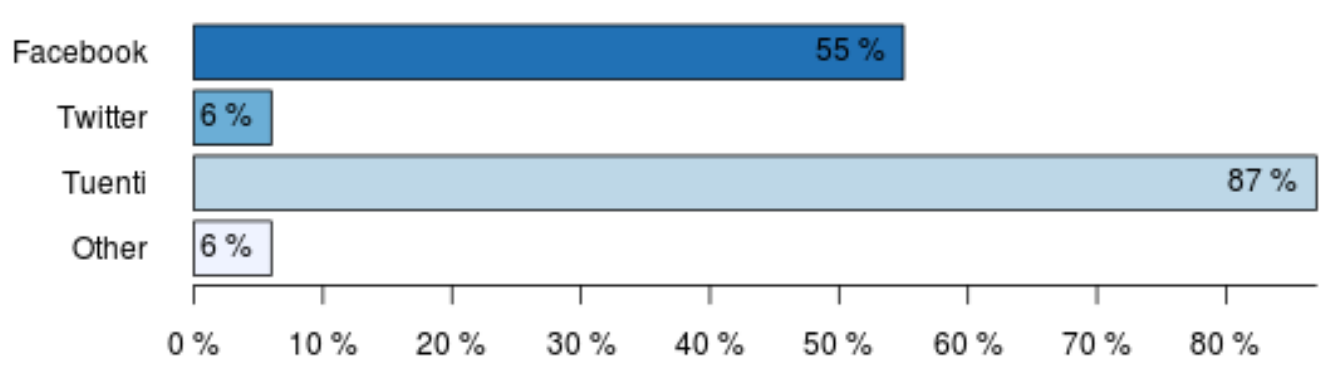

Figure 10. Students utilization of social networks (multiple choice was possible)

Finally, we would like to quote some opinions students expressed in the section: "Other suggestions and comments" about the Babelium Project application (please note that these are exact words from the students, so the reader could find some mistakes): "Funny", "Interesting and useful for working at home and for being assessed", "A good way to develop much more useful activities; furthermore, it allows to get a more personal evaluation/feedback", "A good format for working, easy and enjoyable", "I like it a lot, funny, I have learnt a lot. A good manner to work and learn", "A very suitable resource to develop oral skills", "Interesting and innovative. It is out of the ordinary English classes", "Interesting".

The above comments are from Questionnaire A, but there are more relevant opinions extracted from Questionnaire B, which was about all the educational material used in the course, not just Babelium. The following comments are extracts from the whole answer sheets filled by the students. As shown, the main tool in this research has been cited several times as a very useful activity for improving oral expression: "Doing Babelium Project I think that this project has helped us a lot and I agree with the idea that I have improved my oral skills.", "It has been good, but I think that we will have to do more oral exercises and exams during the course. The Babelium Project is a useful and attractive tool to learn English.", "The most that I like is Babelium Project. I think that we have to study more phonetic and do more exams to improve our English", "The funniest part of Babelium Project has been the "story board". We spent a good time preparing it. I think it was very positive for us.", "I like a lot the idea of the Babelium Project", "I think the most enjoyable thing that we have done is the storyboard, more over it is a different work that we have never done before".

\section{Discussion}

This experience was designed, among other purposes, to improve and extend students' oral skills doing activities in a subject related to the teaching of English as a Second Language. Results show that by using Babelium students have practiced even more hours than they consider necessary to pass an exam on a B2 level. With an average of nearly 36 minutes a day, students are practicing for 3 hours a week (the amount of time estimated by the students themselves necessary to pass the exam), so this data supports our assumption that, compared to experiences from the previous years where no other tool was available, the use of Babelium motivates students to practice speaking. Note that $55 \%$ of the students have practiced more with this application than without it.

The collected data confirms that it is an innovative new tool in the L2 teaching/learning area, as reflected in the answers to the following question: "Before this English course, have you ever been part of or participated in a project like Babelium?", where 100\% of students said that they had never participated in a similar project. Moreover, according to the answers we have received in the questionnaires, students consider Babelium as a 
positive tool to improve their English oral skills as well as it being entertaining and interesting. This could be one of the reasons why they used it so much. Even so, it seems necessary to add a wider range of exercises to make the experience more attractive and enriching.

Another significant result is that still today, in the middle of the technological revolution, when millions of people are interconnected via social networks, sharing personal data and images and using mobile devices all the time for any type of communication, they are suspicious of using webcams to record and show themselves talking in a foreign language. In the case of Second Languages Learners, as suggested in Bello (1999), it is very important to observe students pronouncing and gesticulating, so it is highly recommended to use both the webcam and the microphone to encourage students to confront the feelings of fear and embarrassment in order to obtain a better and more complete experience.

In this section, we also want to show the teacher's impressions about the whole experience and also about the use of Babelium in the class. What follows is a selection of quotes summarizing Montero's opinions as well as some recommendations given to other teachers:

"Second Language Teachers need to understand that there are usually multiple paths that lead to teaching. They should be encouraged to seek out and experiment with new ideas and technologies which can help to decrease enormously the evaluation time, present best real language practices and bring students the opportunity of full time access to the language. In this sense, Babelium presents a useful tool which help both teachers and students."

"Before this academic year (2010-2011), I thought that I was doing my best job while teaching English as a Second Language to my students, but then, I realized that my classes needed something different. Babelium has helped to improve my methodology in order to help my students to acquire language instead of learning rules. Due to Babelium, students knew from the very beginning what I expected of them. After the experience, they realize that their effort was worthwhile and enjoy the benefit of practicing the language through effective performance."

"Before using Babelium, exercise evaluations were neither recorded nor stored in any location. For this reason, I was expected to handle a plethora of devices and formats in which students handed in their recordings of the assigned oral exercises. With the online tool, it is possible to record and store all the audio answers to the exercises in one platform and, in this way, I am able to use the platform to show my students' common errors and best examples of task completion and, moreover, to reuse those resources from year to year."

"Teachers can prepare and share specific exercises to reinforce phonetics, intonation, stress and rhythm such as the reading of a novel fragment. Teachers can also present activities to make sure students have the chance to show their creativeness. One example would be when students are given a group oral presentation assignment about a free topic. Teachers could encourage students to write it first to practice the written skills and then, perform it using a camera as if they were recording a video in the target language. This gives all students the chance to complete the assignment in their own creative style and motivates them to do their best."

Therefore, although it is a must to develop more experiences and measure them, we can conclude that it is possible to integrate the use of new technologies and innovative tools such as Babelium in the teaching of English as a Second Language with proposals that can motivate both students and teachers.

\section{Conclusions and Future Work}

In this research project, we have seen that there is a new innovative online tool that can be used to increase the L2 student exposition to oral practice activities. Results indicate students practice with the application during long periods of time and consider the use of Babelium Project to be positive for improving oral skills.

In addition, teachers now have a new online environment to assess their students' speaking answers and save them in a public, open and shareable repository with best and worst examples of task completion, allowing students to query and consult it whenever they want. Teachers have a major role to play in student motivation for using new technologies while learning a second language. Students know that speaking correctly is hard and they need effective motivational support from teachers and the curricula themselves, and Babelium appears to be an efficient tool to achieve this goal.

The early instructor-adopters of the Babelium tool, based on the good results that our students have shown, have encouraged GHyM and its contributors to share these findings so that other L2 teachers can adopt this tool and the suggested speaking exercises in their classes.

During the February-May 2013 semester, more students from the subject "Second Language II: English" at the University of Basque Country are going to push the limits of Babelium trying to use it also as a tool to assess each other's work in a collaborative way, as a reply to student's opinion about co-evaluation (Figure 11). It will be an 
interesting case study which will allow us to measure the accuracy and reliability of collaborative evaluations.

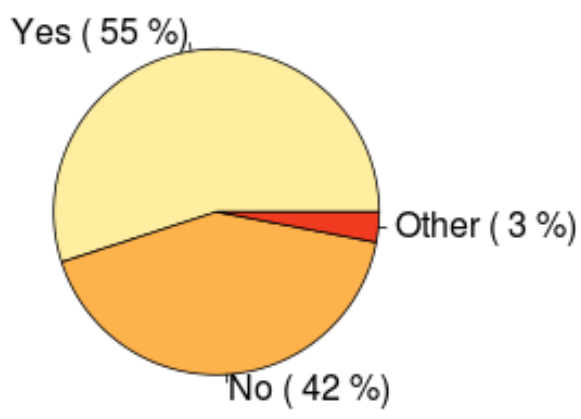

Figure 11. Do you think other classmates' assess could help you to correct your mistakes?

In the near future, we will continue working on the improvement of video exercises. The study described has been developed using a type of exercises that have not been formally categorized. In table 1, we propose a brief oral exercise categorization, partially based on Palloti's work (2010).

Table 1. Categorization of speaking exercise in Babelium

\begin{tabular}{ll}
\hline EXERCISE & DESCRIPTION \\
\hline Free context & $\begin{array}{l}\text { The student visualizes a small fragment of a video about one certain topic. Once } \\
\text { ended, he/she is asked to talk freely about that topic. }\end{array}$ \\
Error detection & $\begin{array}{l}\text { A video with correct and incorrect expressions is shown. After each expression, } \\
\text { the student must repeat the expression (if correct) or correct it (if the expression } \\
\text { is wrong). } \\
\text { These are exercises about dubbing a video clip (somewhat like a karaoke, but } \\
\text { Repetition }\end{array}$ \\
about video fragments instead of music). The difficulty is that repetition has to \\
fit a defined segment of time.
\end{tabular}

Moreover, using appropriate open licenses (such as Creative Commons licenses), L2 teachers will be able to create and share video exercises specifically crafted for improving speaking skills at different language levels. Babelium appears as one of the first online and openly available repository system which allows students the interactive recording of their voices and faces while learning a language.

In view of the experience reception and results, we have worked on extending the architecture of Babelium with a new module that allows teachers to use all the Babelium application functionality inside other familiar scenarios. In order to achieve this aim, the Babelium research group has published an open API (Application Programming 
Interface) that allows this integration. In fact, the Babelium plug-in for Moodle, one of the most extended LMSs in the world, is already available for downloading from the Moodle website for versions 1.9, 2.0, 2.1, and 2.2, and we are on the point of finishing the plug-in for version 2.3.

Following with the idea of spreading Babelium across all potential users, and in view of the fact that Adobe will no longer provide new releases of Flash Player either for Linux (after version 11.2) or for Android (since version 4.0), we are now also working on an HTML5 version, valid for web, Android and iOS systems - the ones used by tablets and smartphones.

\section{References}

Alía, R., González, J., Membrillera, J., Molinero, A., \& Serrano, M. (2005). Dificultades del alumnado español para el aprendizaje del inglés en la educación secundaria. Presented at the VIII Jornadas de intercambio de experiencias educativas, Alcalá de Henares. Retrieved from http://centros5.pntic.mec.es/cpr.de.alcala.de.henares/index.htm

Baralt, M., Pennestri, S., \& Selvandin, M. (2011). Using Wordles to teach foreign language writing. Language Learning \& Technology, 15(2), 12-22.

Bello, T. (1999). New avenues to choosing and using videos. TESOL Matters, 9(4), 1-20.

Bradlow, A. R., Akahane-Yamada, R., Pisoni, D. B., \& Tohkura, Y. (1999). Training Japanese listeners to identify English $/ \mathrm{r} / \mathrm{and} / \mathrm{l} /$ : Long-term retention of learning in perception and production. Perception and Psychophysics, 61(5), 977-985. http://dx.doi.org/10.3758/BF03206911

Cenoz, J., \& García Lecumberri, M. L. (1997). The Acquisition of English Vowels. New Sounds 97 (pp. 55-60). Presented at the Amsterdam Symposium on Acquisition of Second Language Speech, Amsterdam.

Cenoz, J., \& García Lecumberri, M. L. (1999). The Effect of Training on the Discrimination of English Vowels. International Review of Applied Linguistics, 37(4), 261-275. http://dx.doi.org/10.1515/iral.1999.37.4.261

Education First Ltd. (2011). English Proficiency Index Report. Retrieved from http://www.ef.com.es/epi/download-full-report/

Frey, T. J., Houlton, A. L., \& Gruis, E. D. (2010). I can see me: webcams in the classroom. Learning \& Leading, 38(3), 36-37.

Gilete, R. M. (2010). The Explorer of the Chest. Madrid: Portal Editions.

Goldstein, B. A., \& Iglesias, A. (1996). Phonological patterns in normally developing 4-year-old Spanish-English bilingual children. Language, Speech, and Hearing Services in Schools, 31, 153-164. http://dx.doi.org/10.1016/0021-9924(95)00022-4

Gómez, E. (2009). Perception and Production of Vowel Reduction in Second Language Acquisition. Bilbao: University of the Basque Country.

Jiang, X., \& Grabe, W. P. (2011). Skills and strategies in foreign language reading. La lectura en lengua extranjera. London: Portal Editions.

Lodge, D. (1995). Small World. London: Penguin Editorial.

Oxenden, C., \& Latham-Koening, C. (2008). New English file upper-intermediate. Oxford: Oxford University Press.

Paivio, A. (1986). Mental Representations: a dual coding approach. Oxford: Oxford University Press.

Palloti, G. (2010). Doing interlanguage analysis in school contexts. Communicative proficiency and linguistic development (pp. 159-190). EUROSLA Monographs Series 1.

Park, H., \& Lee, A. R. (2005). L2 learners' anxiety, self-confidence and oral performance (pp. 197-208). Presented at the Conference of Pan-Pacific Association of Applied Linguistics.

Tanveer, M. (2007). Investigation of the factors that cause language anxiety for ESL/EFL learners in learning speaking skills and the influence it casts on communication in the target language. University of Glasgow. 